\section{Commentary: Acute type A aortic dissection: When sample size does matter}

\author{
Antonio Miceli, $\mathrm{MD}, \mathrm{PhD},{ }^{\mathrm{a}}$ \\ Francesco Donatelli, Prof, MD, ${ }^{\mathrm{b}, \mathrm{c}}$ and \\ Mattia Galuber, $\mathrm{MD}, \mathrm{PhD}^{\mathrm{a}}$
}

Acute type A aortic dissection (ATAAD) is a lifethreatening condition associated with high mortality and morbidity within the first 48 hours. Operative mortality is high and depends on the patient's morbidities and preoperative clinical condition, and on the extension of aortic dissection. ${ }^{1}$

According to most common risk calculators (eg, Society of Thoracic Surgeons, EuroSCORE), age is an important risk factor for adverse outcomes and has an important role in the decision making for surgery or medical treatment. Bruno and colleagues ${ }^{2}$ found that older patients had a 2-fold increased risk of short-term mortality compared with younger patients, advising conservative management in selected "old" patients. Nevertheless, an study from the International Registry of Acute Aortic dissection on a 20-year experience concluded that surgical management was significantly associated with lower mortality than medical therapy until age 80 years. ${ }^{3}$ For those aged $80-90$ years, mortality was still lower, but the difference was not statistically significant because of limited patient numbers.

From these controversies have risen the ethical dilemma of treatment and the questions of "how old is 'old'?" and "to cut or not to cut?"4 In this issue of the Journal, Bojko and colleagues ${ }^{5}$ address these questions and conclude that early

From the ${ }^{a}$ Department of Minimally Invasive Cardiac Surgery, Cardiothoracic Center, Istituto Clinico Sant'Ambrogio, Gruppo Ospedaliero Sant'Ambrogio; ${ }^{\mathrm{b}}$ Cardiac Surgery, University of Milan; and ${ }^{\mathrm{c}}$ Department of Cardiac Surgery, Cardiothoracic Center, Istituto Clinico Sant'Ambrogio, Milan, Italy.

Disclosures: The authors reported no conflicts of interest.

The Journal policy requires editors and reviewers to disclose conflicts of interest and to decline handling or reviewing manuscripts for which they may have a conflict of interest. The editors and reviewers of this article have no conflicts of interest.

Received for publication March 31, 2020; accepted for publication March 31, 2020; available ahead of print April 18, 2020.

Address for reprints: Antonio Miceli, MD, PhD, Minimally Invasive Cardiac Surgery Department, Istituto Clinico Sant'Ambrogio, Gruppo Ospedaliero SanDonato, Via LG Faravelli 16, 20146 Milano, Italy (E-mail: antoniomiceli79@alice.it).

J Thorac Cardiovasc Surg 2022;163:14-5

$0022-5223 / \$ 36.00$

Copyright (c) 2020 by The American Association for Thoracic Surgery

https://doi.org/10.1016/j.jtcvs.2020.03.153

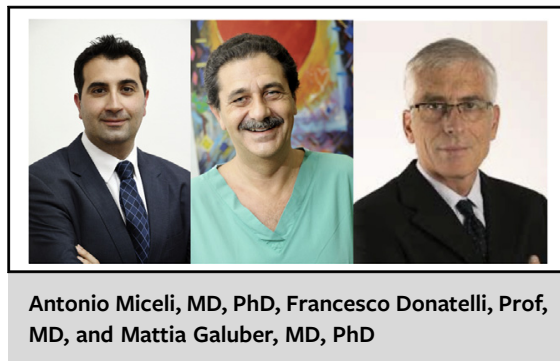

CENTRAL MESSAGE

Age per se is not considered an exclusion criterion for surgery. However, further studies with large sample sizes are needed to confirm this conclusion.

and midterm survival and quality of life after surgery for ATAAD are similar in octogenarians and septuagenarians. Furthermore, octogenarians who survive after the initial operation have comparable long-term survival to an ageand sex-matched population.

The authors' results are excellent and probably outweigh the medical treatment. Nonetheless, this study has some limitations. First, the study is limited by the small sample size; only 70 octogenarians were analyzed, and the large confidence intervals reported in multivariable analysis highlight the low number of events that occurred. Then the median age for the octogenarians was 83 years (interquartile range, 81-85 years), which assumes that most patients age $>85$ received medical treatment. Finally, outcome depends on the weight of the surgical procedure. In the setting of ATAAD, proximal aortic root repair represents the simplest and shortest operation with the least adverse impact on the patient. Compared with septuagenarians, octogenarians received more proximal aortic root repair and only 1 aortic arch replacement.

In conclusion, age per se should not be considered an exclusion criterion for surgery. Bojko and colleagues demonstrated that octogenarian and septuagenarian patients have comparable outcomes in terms of survival and quality of life. However, a poorer preoperative clinical condition and aggressive surgical techniques might be associated with increased morbidity and mortality. An "aortic risk" calculator that takes into account age, risk factors, and patient frailty might aid the decision making process and in selecting patients who will benefit from the surgical procedure over medical treatment. However, we need more numbers. Sample size does matter. 


\section{References}

1. Miceli A, Murzi M, Lio A, Franeti PA, Etz CD, Glauber M. Hybrid approach in acute aortic dissection. In: Edizione E, ed. Innovative for the aortic arch replacement. Torino, Italy: Minerva Medica; 2016.

2. Bruno VD, Chivasso P, Guida G, Vohra HA. Surgical repair of Stanford type A aortic dissection in elderly patients: a contemporary systematic review and meta-analysis. Ann Cardiothorac Surg. 2016;5:257-64.

3. Evangelista A, Isselbacher EM, Bossone E, Gleason TG, Di Eusanio M, Sechtem U, et al. Insight from the international registry of acute aortic dissection: a 20-year experience of collaborative clinical research. Circulation. 2018;137:1846-60.

4. Estera AL, Safi HJ. Aortic dissections in the elderly: ethical dilemma of treatment. Tex Heart Inst. 2012;39:831-3.

5. Bojko MM, Suhail M, Bavaria JE, Bueker A, Hu RW, Harmon J, et al Midterm Outcomes of emergency surgery for acute type A aortic dissection in octogenarians. J Thorac Cardiovasc Surg. 2022;163:2-12.e7. 